\title{
Understanding metal concentration and speciation in motorway runoff
}

\author{
Julia Zakharova ${ }^{a}$, Hamid Pouran ${ }^{a}$, John Bridgeman ${ }^{b}$, Andrew Wheatley $^{c}$, Mohammed Arif $^{\text {a }}$ \\ ${ }^{a}$ University of Wolverhampton, Faculty of Science and Engineering, Wulfruna Street, WV1 $1 L Y$. \\ J.Zakharova@wlv.ac.uk; ${ }^{b}$ University of Bradford; Bradford, West Yorkshire, BD7 1DP; ' Loughborough University, \\ School of Architecture, Building and Civil Engineering Epinal Way, LE11 3TU.
}

\section{Abstract}

Although highway runoff has historically been extensively studied, the increasing complexity of stormwater management means that there are still significant gaps regarding the reduction of soluble metals. The work reported in this paper addresses these challenges by analysing the presence and behaviour of iron, copper and zinc in runoff from junction 24 of the M1 motorway in the UK (peak traffic flow: 30,000 vehicles per hour) and comparing it with other urban sources of metals found in the same catchment (a local brook and sewage treatment works). The sampling site included an interceptor and a treatment lagoon and the event monitoring indicated a trend by which the metals did not change their concentration or particulate soluble proportion immediately, hence showing that pre- and post-storm conditions are important factors when analysing the solubility of metals and their behaviour. The data provided further evidence of the important influence of storm characteristics on metal concentrations in highway runoff, in particular the effects of an antecedent dry weather period (ADWP). In addition, this study also helped us to better understand how the release of sodium the application of de-icer for road maintenance in winter affects the availability of zinc.

Key words: ADWP; de-icer application; highway runoff; soluble metals; SuDS.

\section{Introduction}

Roads and highways may represent a small portion of the impermeable urban catchment area (from 10 to $20 \%$ ), but road runoff could, according to some research, contribute between 35 and $75 \%$ of total metal and $50 \%$ of the total suspended solid (TSS) loads discharged into the receiving water (USGS, 2000). Quantifying and characterising the pollution associated with urban stormwater and identifying and developing appropriate treatment methods have become more important because of the likelihood of more intense storms which may remobilise sediment-bound pollutants. Highway pollutants are diffuse, potentially persistent and toxic (Butler et al., 2006). The continued growth of traffic and revisions to the Water Framework Directive (WFD) where the bioavailability of metals has been incorporated into regulatory practice are making the task of meeting the standards more challenging (Pagotto et al, 2001; Gnecco et al., 2005; Niu et al, 2018). The revised Environmental Quality Standards (EQS) are more rigorous but at the same time strict as they consider, together with hardness, additional environmental parameters such as $\mathrm{pH}$ and Dissolved Organic Carbon (DOC). More information about the factors affecting the bioavailability of metals will be required. Hence the gathering of accurate and comprehensive information should take place as a matter of routine. Moreover, the interpretation of the 
information will demand a better understanding of the behaviour of metals and their speciation (UKTAG, 2013) (for details, please see supplementary information for details).

The most commonly measured metals in highway runoff in the UK are copper $(\mathrm{Cu})$ and zinc $(\mathrm{Zn})$. Copper is released from brake linings during braking and zinc arises from normal tyre wear (Zhang et al., 2015).

Previous studies suggest that the dissolved fraction of copper and zinc varies from source to source and could represent a substantial part of their total form, with the actual percentage being a function of the water chemistry of both the water body and the type of runoff itself. For more detailed information please see supplementary information (SI Table 1). Furthermore, if the dissolved fraction becomes bioavailable, then adverse effects on water bodies might take place. The UK Highways Agency suggests that the main factors affecting metal concentration in runoff are traffic flow, climate, antecedent dry weather periods (ADWP) and rainfall characteristics (Crabtree et al., 2006; Kayhanian et al., 2007).

Long term metal pollution and control in highway runoff is a complex process because of the following factors presented below:

\section{Runoff formation}

The probability of a runoff formation depends on many factors, with heavy rainfall being only one of them. Let us assume that we have a high-intensity rainfall. It does not necessarily mean that it would cause flooding, as the associated physical characteristics of the catchment would affect the runoff formation. For example, an ADWP or the soil's moisture status would have a significant impact. A dry porous soil sorbs water immediately, while the opposite pertains for a saturated soil, especially if it does not have a porous texture.

\section{Runoff treatment and meeting the standards}

If the concentrations of metals exceed the standards, then in such instances the runoff should be treated before discharge, with the level of treatment depending on the dilution available in the receiving water. In some cases, a receiving water body and a final stage of treatment could be combined into one and in such conditions the standards should be applied to the final stage of treatment. This is particularly important for sustainable drainage systems (SuDS) such as ponds and lagoons, the role of which is not only to protect and enhance the groundwater quality and quantity but also to replicate natural systems (Butler et al., 2006). 
The environmental impact of metals in a catchment and their removal by treatment depends on their solubility and attachment to the solids present in the runoff. This binding is affected by the physico-chemical properties of the ambient environment, including $\mathrm{pH}$, ionic strength, temperature, particle size, hardness (base cations), anions, oxidation-reduction potential (redox), and the presence of other elements (USGS, 2000; Ling et al., 2018; Dang et al., 2019). These interactions vary with the location and catchment area. They are also interrelated variables, though some of them, like $\mathrm{pH}$, play a more critical role. These factors are affected by seasonal and temporal changes, as highlighted in other research (Gnecco et al., 2005; Crabtree et al., 2006).

As can be observed, understanding the occurrence of metals in highway runoff and their environmental impact is a complex phenomenon, and we face an even more challenging task when we need to propose in situ treatment methods to remove metals, as suggested by the Environment and Highways Agencies.

\section{Aims and objectives}

This research aims to contribute to our understanding of the presence of metals in and their removal from highway runoff. Here we focus on (1) assessing the factors affecting metal solubility and (2) determining the performance of a typical treatment system for busy road junctions by demonstrating the role of SuDS.

In this study we reflect on the field data that were collected for over a year from one of the busiest motorway junctions in the UK.

The measurements include copper, zinc and iron concentrations. These metals were chosen because copper and zinc have been subject to major revisions of their EQS (UKTAG, 2013). Iron often receives limited attention in studies due to its low toxicity (EQS for $\mathrm{Fe}_{\text {dis }}=1 \mathrm{mg} / \mathrm{l}$; Council of European Communities, 1976), however it could serve as a good model for studying metals with low solubility, for example, aluminium-based coagulants which are used during wastewater treatment to reduce the phosphorus concentration (Comber et al., 2005; Pouran et al., 2017). Besides its application as a de-icing salt, $\mathrm{NaCl}$, is often used for roads maintenance during cold weather, which could affect the behaviour of other metals, including improving their dissolution, 
(Norrstrom, 2005). Therefore, in addition to the above-mentioned experiments, total sodium ( $\left.\mathrm{Na}_{\text {tot }}\right)$ was also analysed as a proxy for de-icing salt.

This study differentiates itself from those conducted previously and demonstrates its importance and novelty in the following ways:

i)-Unlike other research, it is focused solely on the impact of the traffic on the metals' concentrations in the highway runoff and the data was deliberately obtained only from a site where there was no interference from other sources, e.g. sewage discharge or mining. At the same time, the data deriving from that motorway site was compared to data from the water of a pristine brook and two sewage treatment works' final effluent discharges (combined sewerage) to demonstrate the comparison on a catchment level. This helped us to test our first hypothesis, namely that highway runoff would be a major contributor to pollution compared to other urban sources.

ii)-Both the location size and engineering design of the drainage and treatment system allowed us to monitor the entire chain giving rise to runoff formation and analyse the whole existing treatment train of the runoff.

iii)-As part of the monitoring of the runoff formation, both pre- and post-storm conditions were analysed and this data proved to be crucial for studying the behaviour of soluble pollutants. Thus, our second hypothesis is that the ratio of dissolved to particulate in metals does not change immediately; hence, in conjunction with a rainfall event, determinations of pre and post storm metal concentrations as well as those of their surrogates are crucial in order to be able to report fully on metal bioavailability.

While this is a case study on the impact of the traffic on the metals concentration in highway runoff, the results and the knowledge derived from them about the metals' fate and behaviour can be transferred to different sites and scenarios in the same climatic zone. Accordingly, the principle of SuDS could be embraced in those locations with a primary goal of improving water quality in water bodies by tackling urban diffuse pollution. The sites might include residential, commercial areas, schools as well as other public and private sectors.

\section{Methods}

The experimental design was set up in such a way that both of the hypotheses mentioned in the introduction would be tested.

\section{Sampling sites}


The test site was a junction formed by three major roads in the UK: the M1 and M42/A42 motorways and the A50 dual carriageway (J24 at Kegworth, Leicestershire, UK) with peak traffic flows of 30,000 vehicles an hour. This junction was rebuilt in 1996 and it now includes a highway runoff interceptor and a SuDS lagoon (Figure 1).
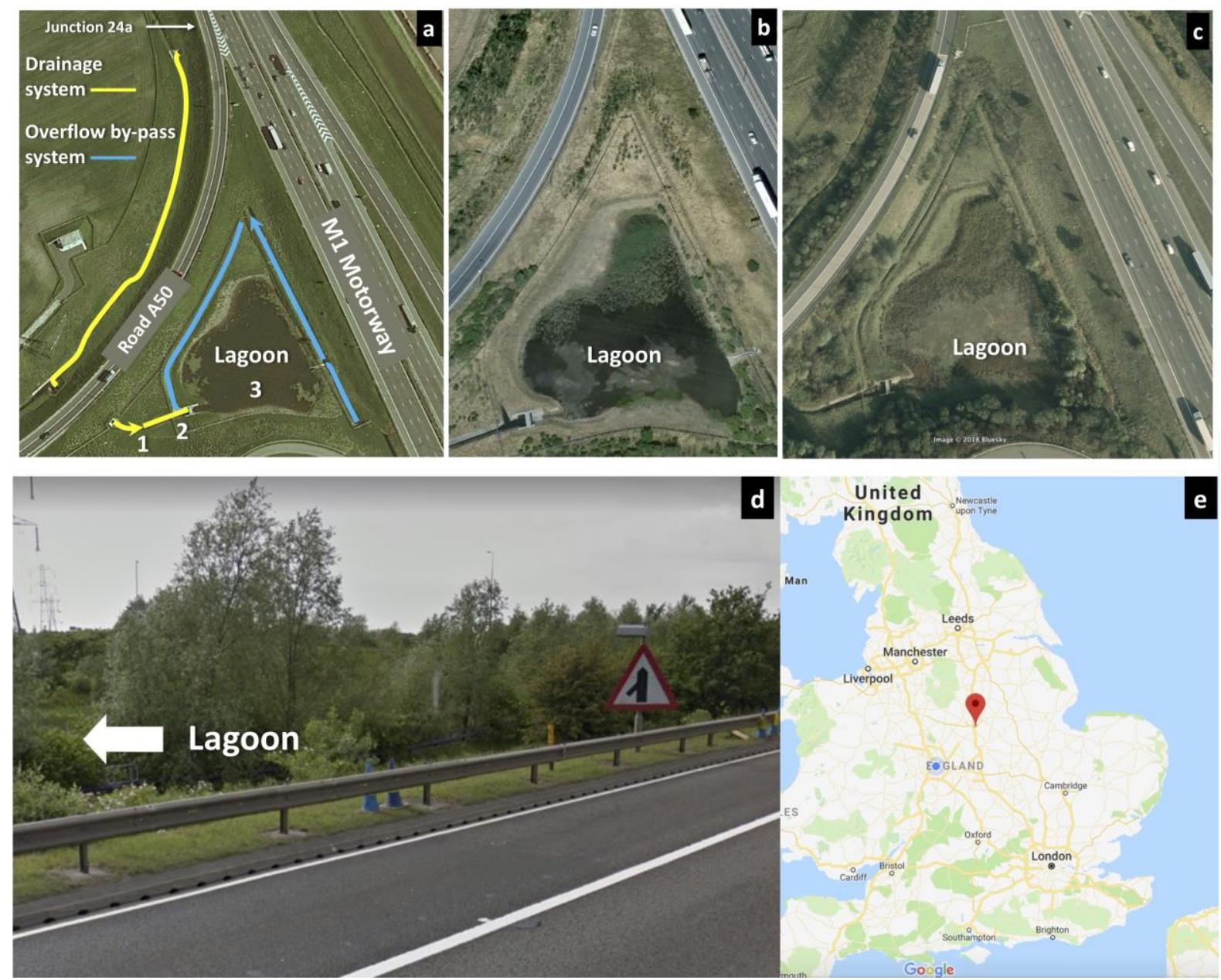

Fig.1 Sampling site on the M1, J24A.

(a) Aerial view of the SuDS lagoon. Runoff sampling points from the M1 (1 - before the interceptor; 2 - after the interceptor; 3 - adjacent to the lagoon outlet.) in 2000 (b) Aerial view of the lagoon during the sampling time , 2008-2009, and (c) the current status of the sampling area (2020). In this figure (d) the side view of the lagoon from the highway is shown, (e) also shows the location of the sampling area on the UK map (Image credit: Google Earth Pro).

During rainfall events, after the runoff leaves the highway, it flows directly into an inlet (sampling point 1). It then runs along a ditch adjacent to the motorway, combined with the drainage from the A50 slipway, discharges into an interceptor - a trap that is used to filter out hydrocarbon pollutants to prevent the contamination of streams by fuel from highway runoff (sampling point 2 ) and then into a lagoon (sampling point 3), as seen in Figure 1. The volume of the ditch, including the connected channel (overflow by-pass system), is approximately $25 \mathrm{~m}^{3}$. The system drains an impermeable area of approximately $3,000 \mathrm{~m}^{2}$. The volume of the lagoon is $2000 \mathrm{~m}^{3}$, with an average depth of $0.9 \mathrm{~m}$. There are no other activities in the adjacent area, apart from traffic, that could contribute to the metal concentrations in the water held in the lagoon. The lagoon was 
functioning properly during the sampling period (Figure 1b). However, assessing Figure 1c, some visual changes in the lagoon may be noticed. To ensure that the system continues to function correctly, the following measures need to be put in place (LI, 2014):

(1) Planned preventative maintenance should occur to ensure that the channels are clear of silt;

(2) Vegetation around the facility should be managed to facilitate easy access;

(3) Annual monitoring needs to be conducted to establish the continuing efficient performance of the facility.

If these activities are put in place then the facility should continue to function correctly and deliver satisfactory long term performance well into the future.

\section{Woodbrook}

To compare the discharge from the M1 with a control, a local brook (Woodbrook) in the same catchment area was sampled. The Woodbrook - historically the catchment of the local water supply, Nanpantan - is an overflow stream from a local, decommissioned water treatment works reservoir. The average flow rate in the brook during dry weather is $50 \mathrm{l} / \mathrm{s}$. The area upstream of the sampling points consist of agricultural land lying close to its source ( $3 \mathrm{~km})$ in Charnwood. The catchment area is approximately $25.5 \mathrm{~km}^{2}$.

\section{Sewage treatment works}

Samples were also analysed from the final effluent discharge points of two local sewage treatment works (STW) (A [Population equivalent $(\mathrm{PE})=55,000-68,000$; primary sedimentation and activated sludge]; and $B$ [PE $=20,000-25,000$; primary sedimentation and trickling filters]).

\section{Conditions of runoff formation for the studied catchment area}

When the runoff from the catchment reaches the inlet ( $1^{\text {st }}$ sampling point), a proportion will be lost en route from the inlet to the lagoon as a result of percolation and trapping by vegetation. The losses are a function of ADWP. Equation (1) shows the relationship between the runoff volume $\mathrm{V}_{\text {runoff }}$ and the rainfall depth $\mathrm{H}$ (in millimetres) for the catchment area $\mathrm{F}=3000 \mathrm{~m}^{2}$, with the runoff coefficient $\Psi$ taken as 0.9 for tarmac (DFT, 2017).

$$
V_{\text {runoff }}=10^{5} \mathrm{HF} \Psi
$$


The above equation helps us to calculate the volume of the expected runoff based on the rainfall depth. Figure 2 shows the volume of the runoffs $\left(\mathrm{m}^{3}\right)$ that would occur after rainfalls with a depth of 1 to $10 \mathrm{~mm}$ in the ditch. The ditch volume is approximately $25 \mathrm{~m}^{3}$.

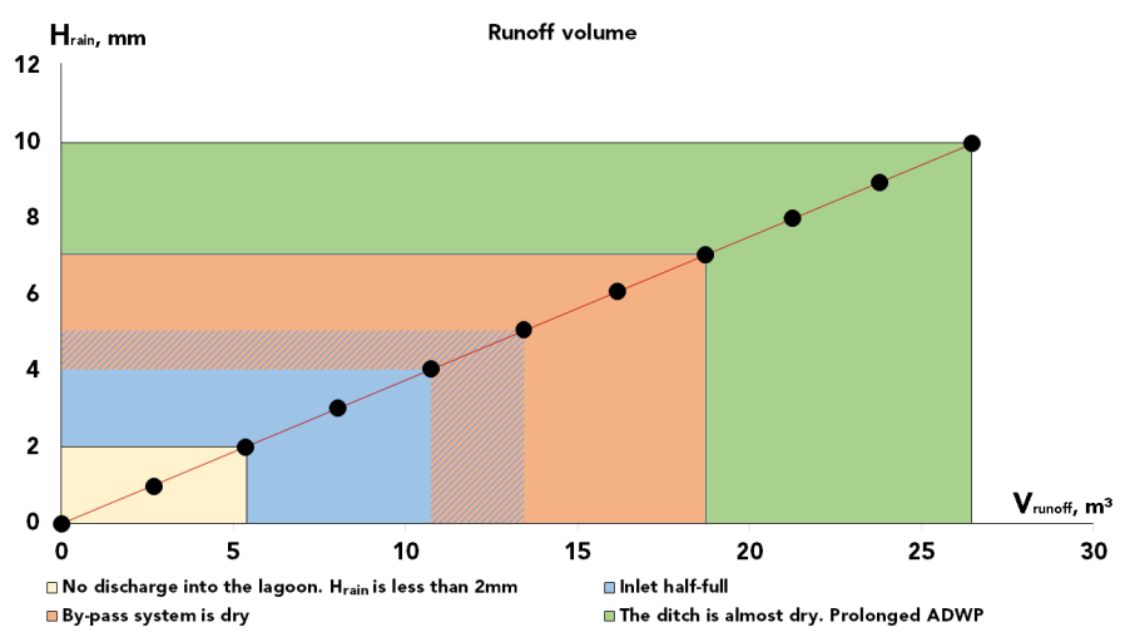

Fig. 2 The expected volume of the runoff $\left(\mathrm{m}^{3}\right)$ after rainfalls with a depth of 1 to $10 \mathrm{~mm}$ in the ditch

Table 1 suggests three different scenarios for the water flowing into the ditch. It was noticed that there was an infiltration loss of up to $3 \mathrm{~mm}$ within the ditch because of the clay bed's presence in the system. So, the rainfall events with a $\mathrm{H}_{\text {rain }}$ of less than $2 \mathrm{~mm}$ would not have produced sufficient runoff for any discharge into the lagoon to have been observed, unless the system was full.

Table 1 State of the ditch depending on the ADWP

\begin{tabular}{cccc}
\hline Scenario & $\begin{array}{c}\text { Representative antecedent } \\
\text { conditions }\end{array}$ & $\begin{array}{c}\text { Remaining capacity of the } \\
\text { ditch, } \mathbf{~ m}^{\mathbf{3}}\end{array}$ & $\begin{array}{c}\mathrm{H}_{\text {rain }} \text { to reach bank-full } \\
\text { conditions, } \mathbf{~ m m}^{*}\end{array}$ \\
\hline 1 & $\begin{array}{c}\text { The ditch is dry/almost dry, } \\
\text { (prolonged ADWP) }\end{array}$ & $\approx 20$ & $7(10)$ \\
\hline 2 & By-pass system is dry & $\approx 10$ & $4(7)$ \\
\hline 3 & Inlet half-full & $\approx 5$ & $2(5)$ \\
\hline
\end{tabular}

${ }^{*}$ There is an approximate infiltration loss of 3mm within the ditch because of the clay's presence, which raises the rainfall depth required to reach the bank-full condition, as seen from the Table above.

\section{Sample collection}

In order to study the metals' solubility in the lagoon and thus investigate how natural processes and conditions (rainfall, temperature and evaporation) may affect the metals' speciation, grab samples were collected from the lagoon during dry weather from April 2008 to January 2009.

To characterise the final stage of treated runoff during wet weather, samples were collected from the lagoon following four storm events. Rainfall events needed to be of sufficient volume, as was the case on those four occasions, to generate a discharge into the lagoon (see Fig. 2 and Eq. 1). 
To determine the performance of a typical treatment system, a major storm event was observed in May 2008 together with the pre-storm and post-storm conditions. The chosen sample points facilitated the gaining of an insight into how the metals' concentrations changed through the treatment train.

The sampling was focused on the motorway runoff and the rural brook because by contrast greater buffering of storms is available in sewage works and, accordingly, changes in the metal concentrations in the sewage effluent were expected to occur more gradually.

\section{Sample preparation}

Grab samples were taken from the water surface, thus avoiding disturbance of the bed sediment. Pre-washed 1 litre polyethylene bottles, pre-soaked in $10 \% \mathrm{HNO}_{3}$, were used. Before sampling, each bottle was rinsed twice with the sample source. Subsamples for the analysis of metals (100ml aliquots) were immediately acidified with concentrated $\mathrm{HNO}_{3}(5 \mathrm{ml} / \mathrm{l})$. For dissolved metal analysis, a similar $100 \mathrm{ml}$ sample was filtered under vacuum through a millipore $0.45 \mu \mathrm{m}$ pre-acidwashed membrane filter and stored in acid-washed plastic bottles. The filtered samples were similarly acidified with concentrated $\mathrm{HNO}_{3}$ to $\mathrm{pH}<2$. Samples for other analyses (TSS, electrical conductivity (EC), hardness) were stored at $4^{\circ} \mathrm{C}$ until analysis had been performed within 24 hours. More information about measurements of these parameters as well as calibration of the instrument can be found in the supplementary information.

\section{Sample analysis}

Total metals were analysed by the aqua regia method (APHA, 2005) using microwave digestion, performed in a CEM Mars Xpress microwave, and $30 \mathrm{ml}$ of sample was used which had been acidified with $2 \mathrm{ml}$ of concentrated $\mathrm{HNO}_{3}$ and $5 \mathrm{ml}$ of concentrated $\mathrm{HCl}$. When the samples were cooled, they were filtered through Whatman No.1 paper and diluted with distilled deionised water to $50 \mathrm{ml}$ in volumetric flasks. For quality assurance purposes, blanks and internal standards were included. Total and dissolved metals were measured with an ICP-OES analyser (Thermo Jarrel Ash Atom Scan 16). Whilst the ICP-OES's detection limit for each of the tested elements is a function of wavelength, for all three determinants considered the limit of detection was $0.002 \mathrm{mg} / \mathrm{l}$. For more information on the calibration of the instrument as well as quality control for the chemical analysis, please see supplementary information.

\section{Sample size (Data processing and analysis)}


Metal concentrations in the runoff may vary widely according to the weather conditions. The variability in weather conditions and long-term trends will affect the statistical reliability of the results and, ideally, continued work will always be needed to adjust the means and range of values determined in any further study. As demonstrated in Figure 1c, the lagoon shows clear and notable physical differences which made it challenging to use consistent methodology to collect data. The lagoon's appearance and, hence, its physical conditions gradually started to change from 2010 onwards (with more reeds and vegetation present) while at the same time it became more shallow and turbid. If, therefore, sampling had been continued in the lagoon it would have lead the research programme into working on the basis of non-comparable conditions which would have resulted in its obtaining inconsistent data from a wayward experimental set-up.

\section{Results and Discussion}

Not only does this section make reference to different weather conditions (dry/wet) but also to a variety of scenarios and consequences which arose from the research campaign that was directed to the testing of our two hypotheses.

The following tables provide the supporting data and analysis of the effects of the weather conditions:

Table 2 - Stormwater data - Data taken from the M1 during storm flow conditions

Table 3 - Stormwater data - Data from Woodbrook during stormflow conditions

Table 4 - Dry weather - Data from the lagoon

Table 5 - Dry weather - Data from Woodbrook

The information from Tables 2 - 6 supports our first hypothesis, namely that highway runoff constitutes a major source of metal pollutants in the catchment, among other sources.

Figures 4 and 5 support the second hypothesis regarding the importance of pre- and post-storm characteristics.

This section also describes the effectiveness of the runoff treatment system as well as the importance of the EQS as a tool for measuring the impact of metal concentration (Table 7).

In the following paragraphs, 'dry weather' refers to conditions with no rain and the term 'wet weather condition' indicates that a specific rainfall event produced an actual discharge into the lagoon (as per Table 1 and Figure 2).

The lagoon as a final stage of treated highway runoff 
Table 2 summarises the storm water data during wet weather (July 2008 and January 2009), representing the final stage of treated runoff during wet weather, where the EQSs should be applied. These data are limited by or defined as arising in conditions when there has been sufficient rainfall to cause actual discharge from the separator into the lagoon itself. The same situation was described by Geronimo et al., 2014 who, while monitoring the treatment system for urban stormwater runoff from TSS and metals, found that out of 11 rainfall events studied only six were able to generate and produce a discharge.

Table 2 Stormwater data from the M1 during storm flow conditions $\left(n=4^{*}\right)$

\begin{tabular}{lllll}
\hline Contaminant & $\begin{array}{l}\text { Concentration } \\
\text { range }(\mathrm{mg} / \mathrm{I}) \text {, apart } \\
\text { from EC }\end{array}$ & Mean value & SD** & $\mathrm{C}_{\mathrm{v}}^{* * *}$ \\
\hline Fe tot & $1.133-1.212$ & 1.164 & 0.038 & 0.033 \\
Fe dis & $0.018-0.212$ & 0.111 & 0.107 & 0.962 \\
Cu tot & $0.002-0.161$ & 0.068 & 0.079 & 1.160 \\
Cu dis & $0.002-0.021$ & 0.013 & 0.006 & 0.456 \\
Zn tot & $0.123-0.201$ & 0.159 & 0.042 & 0.263 \\
Zn dis & $0.02-0.036$ & 0.029 & 0.007 & 0.231 \\
TSS & $8.5-40$ & 23.7 & 17.08 & 0.719 \\
EC & $280-2000 \mu \mathrm{S} / \mathrm{cm}$ & 1053.8 & 877 & 0.833 \\
& & & \\
\hline${ }^{*}$ number of events sampled & & & \\
${ }^{* * *}$ standard deviation & & &
\end{tabular}

The data obtained from Woodbrook during wet weather is shown in Table 3.

Table 3 Data from Woodbrook during stormflow conditions $\left(n=4^{*}\right)$

\begin{tabular}{lllll}
\hline Contaminant, & $\begin{array}{l}\text { Concentration } \\
\text { range }(\mathrm{mg} / \mathrm{l}) \text {, apart } \\
\text { from EC }\end{array}$ & Mean value & SD** & $\mathrm{C}_{\mathrm{v}}{ }^{* * *}$ \\
\hline Fe tot & $1.482-2.515$ & 1.971 & 0.476 & 0.242 \\
Fe dis & $0.077-0.263$ & 0.188 & 0.083 & 0.443 \\
Cu tot & $0.011-0.103$ & 0.050 & 0.039 & 0.794 \\
Cu dis & $0.002-0.003$ & 0.003 & 0.001 & 0.182 \\
Zn tot & $0.053-0.079$ & 0.062 & 0.012 & 0.190 \\
Zn dis & $0.003-0.014$ & 0.007 & 0.005 & 0.660 \\
TSS & $21-52$ & 35.12 & 13.22 & 0.376 \\
EC & $360-500 \mu \mathrm{S} / \mathrm{cm}$ & 415 & 59.7 & 0.144 \\
\hline
\end{tabular}

${ }^{*}$ number of events sampled

** standard deviation

${ }^{\star \star *}$ coefficient of variation

Both for the M1 and Woodbrook all samples showed notable variations and differences under wetweather conditions. Taking the mean values for the M1 and Woodbrook, then iron was always found to exhibit the highest concentration, as might be expected. 
Both total and dissolved metal concentrations were found to exhibit the hierarchy $\mathrm{Fe}>\mathrm{Zn}>\mathrm{Cu}$, as shown in Tables $2-3$.

Pagotto et al. (2000), when studying the influence of pavement type on the runoff quality along the north ring road in France (where the mean daily traffic is approximately 24,000 vehicles) reported the same order of $\mathrm{Cu}$ and $\mathrm{Zn}$ as is given in our results $(\mathrm{Zn}>\mathrm{Cu}$ ). Hallberg et al. (2007), on analysing three metals, just as in our study, i.e. Fe, $\mathrm{Cu}$ and $\mathrm{Zn}$, found the same order in metal concentrations in their study of the seasonal variations in metals in highway runoff from a trunk road in Stockholm. Their values are higher than those presented here because of the different drainage systems in use in Stockholm and the more extreme cold weather. For example, in winter the TSS concentration in runoff in Stockholm reached $1500 \mathrm{mg} / \mathrm{l}$, with a maximum value of around $5000 \mathrm{mg} / \mathrm{l}$ and $\mathrm{Fe}_{\text {tot }}$ of $226 \mathrm{mg} / \mathrm{l}$. Despite these large values of $\mathrm{Fe}_{\text {tot }}$, the $\mathrm{Fe}_{\text {dis }}$ concentration given in Hallberg et al. (2007) did not exceed $1 \mathrm{mg} / \mathrm{l}$ (with a maximum value of $0.57 \mathrm{mg} / \mathrm{l}$ ) and this was comparable with data presented in this paper $\left(\mathrm{Fe}_{\mathrm{dis}}=0.212 \mathrm{mg} / \mathrm{L}\right)$, confirming its very low solubility. The average for $\mathrm{Fe}_{\text {tot }}$ in results presented here during wet weather in winter was 1.212 $\mathrm{mg} / \mathrm{l}$.

Impact of the metals' solubility due to natural processes

Table 4 provides a summary of the data obtained from the lagoon during dry weather (April 2008 - January 2009). The dry-weather data are needed not only for comparative purposes with the wet weather conditions but also to analyse how natural processes, e.g. evaporation, may affect metal speciation and water quality in the lagoon.

Table 4 Data from the lagoon during dry weather conditions $\left(n=15^{\star}\right)$

\begin{tabular}{llccc}
\hline Contaminant & $\begin{array}{l}\text { Concentration range } \\
(\mathrm{mg} / \mathrm{l}) \text {, apart from EC }\end{array}$ & Mean value & SD** & $\mathrm{C}_{\mathrm{v}}^{* * *}$ \\
\hline Fe tot & $0.177-0.526$ & 0.269 & 0.085 & 0.316 \\
Fe dis & $0.029-0.066$ & 0.049 & 0.026 & 0.528 \\
Cu tot & $0.003-0.041$ & 0.014 & 0.013 & 0.913 \\
Cu dis & $0.002-0.006$ & 0.003 & 0.002 & 0.749 \\
Zn tot & $0.033-0.08$ & 0.05 & 0.015 & 0.290 \\
Zn dis & $0.005-0.069$ & 0.023 & 0.017 & 0.730 \\
TSS & $3.2-23.95$ & 14.1 & 13.1 & 0.931 \\
EC & $370-1070 \mu \mathrm{S} / \mathrm{cm}$ & 725 & 282 & 0.389 \\
\hline
\end{tabular}

* number of events sampled

${ }^{* *}$ standard deviation

${ }^{* * *}$ coefficient of variation 
The data obtained from Woodbrook during dry weather is shown in Table 5.

Table 5 Data from Woodbrook during dry weather conditions $\left(n=12^{*}\right)$

\begin{tabular}{lllll}
\hline Contaminant & $\begin{array}{l}\text { Concentration } \\
\text { range }(\mathrm{mg} / \mathrm{l}) \text {, apart } \\
\text { from EC }\end{array}$ & Mean value & $\mathrm{SD}^{*}$ & $\mathrm{C}_{\mathrm{v}}{ }^{* *}$ \\
\hline Fe tot & $0.125-0.479$ & 0.264 & 0.115 & 0.434 \\
Fe dis & $0.011-0.182$ & 0.062 & 0.057 & 0.919 \\
Cu tot & $0.002-0.018$ & 0.010 & 0.008 & 0.808 \\
Cu dis & $0.002-0.007$ & 0.003 & 0.004 & 1.371 \\
Zn tot & $0.027-0.055$ & 0.044 & 0.008 & 0.181 \\
Zn dis & Traces -0.019 & 0.009 & 0.009 & 0.965 \\
TSS & $4-12$ & 7.2 & 3.02 & 0.418 \\
EC & $420-755 \mu \mathrm{S} / \mathrm{cm}$ & 551 & 130.7 & 0.237 \\
\hline${ }^{*}$ number of events sampled & & & \\
${ }^{*}$ standard deviation & & &
\end{tabular}

Taking the mean values (from Tables $4-5$ ) iron again in all species, like during wet weather, was always found in its highest concentrations. It was found in its particulate form, which increased in proportion to the amount of solids discharged during wet weather (see Tables 2 and 3), which could be mobilised by the $1^{\text {st }}$ flush of the storm (Sansalone and Buchberger, 1997). This is attributable to Fe having become attached to the particulate matter.

Dissolved Zn concentration from the M1 during dry weather was $60 \%$ higher in comparison to Woodbrook during the same conditions, although the total concentration of $\mathrm{Zn}$ from Woodbrook was around 10\% less. Nelson et al. (2009) also reported that zinc could be released during dry conditions due to a number of mechanisms for mobilisation, such as cation exchange, chloride complex formation and colloid breakdown or dispersion, with released organic matter and/or clay complexes. This suggests that pre-storm and post-storm conditions are important subjects for study, as they help to obtain the full picture of metal behaviour and speciation, which is crucial in the light of the metal bioavailability analysis.

$\mathrm{Zn}$ demonstrated the same attachment to particles, like iron, although less distinctive but not in May when major increases in flow re-suspended colloidal and particulate solids in both parts of the SuDS. A more detailed analysis on the proportion of dissolved metals from the M1 and Woodbrook is available in the supplementary information (SI Table 4 and SI Table 5).

In this particular study the changing behaviour of zinc due to the application of de-icer salt $(\mathrm{NaCl})$ was noted. The mechanism for $\mathrm{Zn}$ mobilisation will be described later in this section. 
The concentrations of dissolved and total $\mathrm{Cu}$ and $\mathrm{Zn}$ in M1 runoff were at their highest in May (the major event flush). For details of experimental analysis, the proportion of dissolved metals from the M1 and Woodbrook is available in the supplementary information (SI Table 6).

The most striking result belongs to the month of May, which was initially dry (no rain from $5^{\text {th }}-24^{\text {th }}$ May, except for $16^{\text {th }}$ and $17^{\text {th }}$ May with $1.1 \mathrm{~mm}$ and $0.4 \mathrm{~mm}$ respectively) and then wet (rainfall events of $4.1 \mathrm{~mm} ; 9.1 \mathrm{~mm} ; 15.8 \mathrm{~mm} ; 10.7 \mathrm{~mm}$ and $4 \mathrm{~mm}$ on $25^{\text {th }}, 26^{\text {th }}, 27^{\text {th }}, 28^{\text {th }}$ and $29^{\text {th }}$ May respectively; Figure 3).

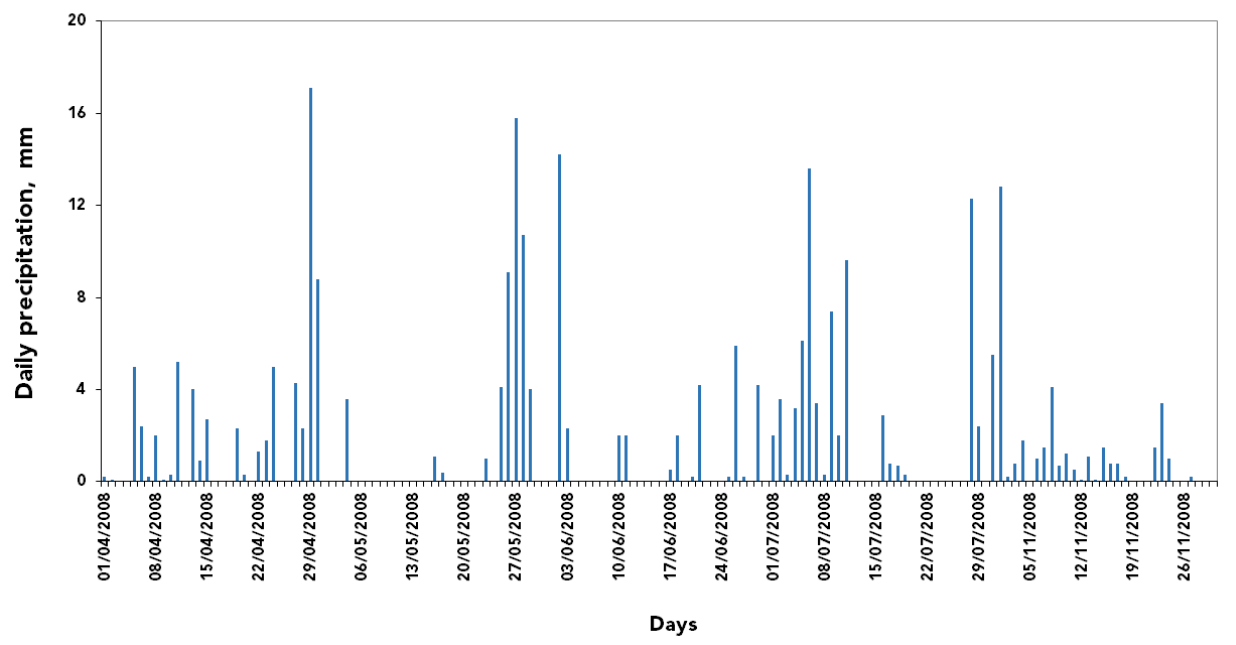

Fig.3 Daily precipitation from April to July and also November 2008

It should be noted, however, that those rains which took place and were recorded on the $16^{\text {th }}$ and $17^{\text {th }}$ May did not produce enough runoff to generate a discharge from the lagoon. It appeared that the whole amount of precipitation was either retained by vegetation or percolated into the ground. The metal concentrations measured at the M1 site in May are disproportionately high when compared to the TSS and values for the other months. This is explained by an analysis of the sampling dates (Fig. 4) and rainfall pattern (Fig. 3).

The influence of pre-and post-storm characteristics on the performance of a typical treatment system

Fig. 4 demonstrates a performance of a typical treatment system which was observed in connection with the sampling of the rainfall event on the $27^{\text {th }}$ May as well as the associated pre storm conditions (background data), $21^{\text {st }}$ May and post-storm conditions (monitoring the changes in metal concentration). For the comparison, account is taken of the wet weather, the rain itself and previous dry weather. It should be noted that standard deviation (SD) for $\mathrm{Cu}_{\text {dis }}$ in interceptor was negligible (less than 0.5) (Fig. 4d). 
a)

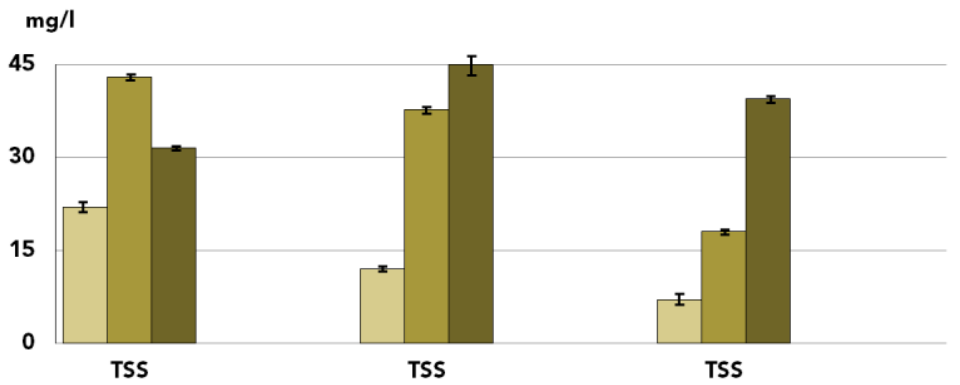

$\begin{array}{lll}\text { Inlet } & \text { Lagoon } \\ \end{array}$

$\square$ Before storm, 21/05/08 $\square$ Storm, 27/05/08 $\square$ After storm, 30/05/08
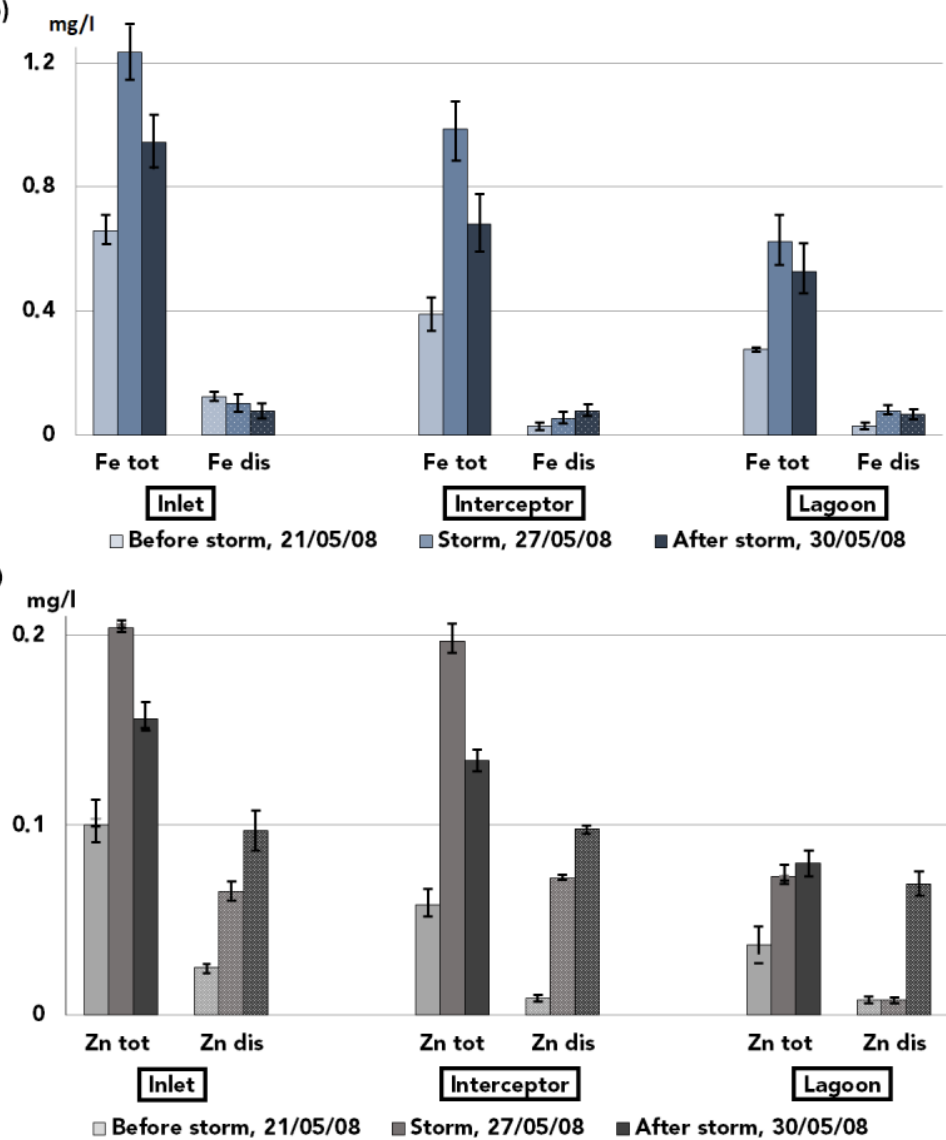

d) $\mathrm{mg} / \mathrm{l}$

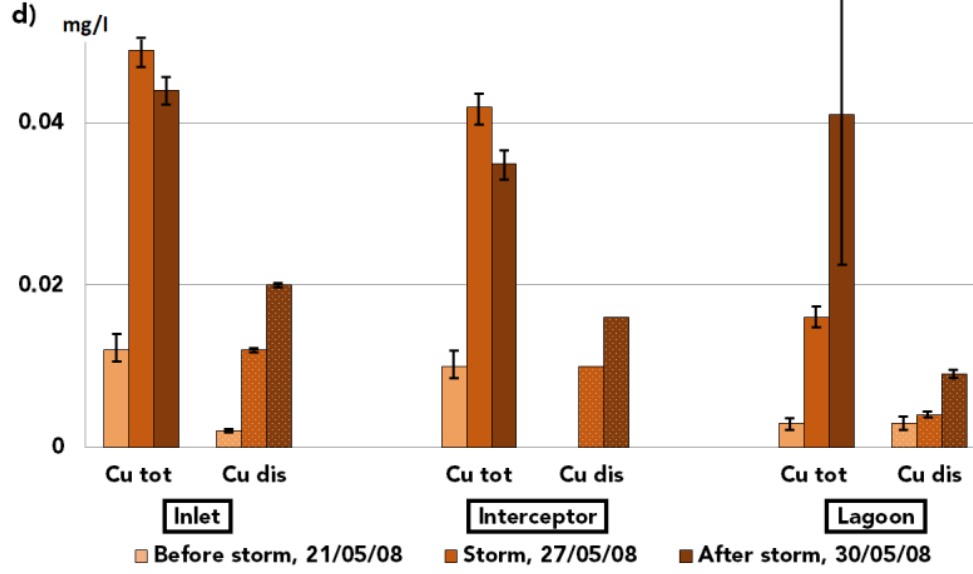

Fig.4 Comparison of pollutant removal from different sample points (as per Fig. 1a) resulting from the May storms (single triplicate samples). a) TSS; b) Fe; c) Zn; d) Cu 
During the sampling time, May was predominantly dry until the $25^{\text {th }}$ (the sampling had been infiltration. Storm events then occurred between the $25^{\text {th }}$ and $29^{\text {th }}$ May (total rainfall from $25^{\text {th }}$ to $29^{\text {th }}$ May $\left.=43.7 \mathrm{~mm}\right)$ and samples were taken during $\left(27^{\text {th }}\right.$ May) and after these storms ( $30^{\text {th }}$ May). This facilitated an analysis of the performance of the interceptor and lagoon when functioning as a treatment system for highway runoff. One of the main phenomena observed in connection with that storm event was the re-suspension of sediment from both the interceptor and lagoon (Fig. 4a), which not only increased the total concentration of metals but also affected the percentage of their dissolved fraction in the longer term.

Comparing the ratio of dissolved to total metals, $\mathrm{Zn}_{\text {dis }}$ (the major pollutant in dry weather) reached a peak of $86 \%$ of the total concentration after the storm $\left(30^{\text {th }}\right.$ May at the lagoon, Fig. $4 \mathrm{c}$ ). By comparison, for the same sample point, the ratio was $22 \%$ and $11 \%$ on $21^{\text {st }}$ and $27^{\text {th }}$ May, respectively. It is suggested that these results demonstrate the potential for the re-release of soluble metals captured in the sediment of interceptors and lagoons after a dry period. This supports our hypothesis that metal concentrations do not change their partitioning immediately. The results obtained by Sansalone and Buchberger (1997) while analysing partitioning of metals during a rainfall event on a heavily travelled highway (150,000 vehicles per day on average) in Cincinnati, Ohio supported our statement by highlighting their finding that partitioning of metals over the first 24 hours was not changed drastically. Thus, when a 3 I sample was analysed portion by portion it was found that $24 \mathrm{hr}$ period had a minor influence on partitioning of metals that had been initially dissolved, e.g. zinc, or particle-bound, e.g. iron. In their case it was the copper that underwent some fluctuations in its partitioning and they inferred that this behaviour might be common for those metals whose partitioning is neither predominantly dissolved nor predominantly particle-bound.

The results also suggest the possibility of long-term pollutant inputs. Previous work has suggested that this is a result of colloid breakdown with released soluble metals (Nelson et al., 2009). This effect would not be expected to occur in Woodbrook because of the different types of settlement and different hydraulic designs of the systems. During rainfall events, the velocity of Woodbrook increases, which results in the disturbance of particles from the bed of the stream, as well as the erosion of soil. The hydraulic regime of the M1 system includes a low- flow ditch, separator and lagoon which are quiescent and, thus, most solids would be expected to settle. The importance of hydraulic regime in terms of deterioration of metals removal at STWs was reported by Rossin et al, 1983. 
Table 6 includes other potentially influential water quality parameters which will affect metal solubility ( $\mathrm{pH}$, hardness and sodium, $\mathrm{Na}$, concentration).

Table 6 Concentrations of indicator metals with dissolved and suspended solids (wet weather)

\begin{tabular}{|c|c|c|c|c|c|c|}
\hline \multirow{3}{*}{$\begin{array}{l}\text { Pollutant, } \\
\text { mg/l, } \\
\text { except EC } \\
\text { and pH } \\
\text { TSS }\end{array}$} & \multicolumn{2}{|c|}{ M1 (post treatment) } & \multicolumn{2}{|c|}{ Woodbrook } & \multirow{2}{*}{$\begin{array}{c}\text { STW A } \\
\text { mean }\left(n=8^{*}\right) ;\end{array}$} & \multirow{2}{*}{$\begin{array}{c}\text { STW B } \\
\text { mean }(n=8) ;\end{array}$} \\
\hline & July & January & July & January & & \\
\hline & 9.5 & 37 & 25.7 & 44.5 & 9.4 & 14 \\
\hline $\mathrm{EC}, \mu \mathrm{S} / \mathrm{cm}$ & 335 & 1780 & 385 & 450 & 996 & 915 \\
\hline $\mathrm{pH}$ & 6.8 & 7.5 & 7.5 & 7.5 & 7.26 & 7.3 \\
\hline $\mathrm{Na}$ & 40.7 & 339.9 & 19.2 & 39.2 & $\mathrm{n} / \mathrm{a} * *$ & $\mathrm{n} / \mathrm{a}$ \\
\hline Hardness & 100 & $\mathrm{n} / \mathrm{a}$ & 265 & $\mathrm{n} / \mathrm{a}$ & 309 & 238 \\
\hline $\mathrm{Cu}$ tot & 0.002 & 0.161 & 0.044 & 0.057 & 0.005 & 0.017 \\
\hline Cu dis & 0.002 & 0.002 & 0.003 & 0.003 & 0.004 & 0.013 \\
\hline Zn tot & 0.157 & 0.123 & 0.069 & 0.055 & 0.060 & 0.054 \\
\hline Zn dis & 0.034 & 0.02 & 0.006 & 0.008 & 0.051 & 0.046 \\
\hline Fe tot & 1.155 & 1.212 & 1.578 & 2.363 & 0.060 & 0.118 \\
\hline Fe dis & 0.204 & 0.018 & 0.125 & 0.251 & 0.033 & 0.077 \\
\hline
\end{tabular}

- $\quad$ total rainfall for July $76.4 \mathrm{~mm}$

- $\quad$ total rainfall for January $60 \mathrm{~mm}$

- $\quad$ amount of rainfall observed in July during sampling day $6 \mathrm{~mm}$

- amount of rainfall observed in January during sampling day $6.5 \mathrm{~mm}$

- $\quad$ based on triplicate samples of a single storm event, except sewage works

- $\quad$ * number of events sampled

- $\quad{ }^{* *}$ not avalable

The Table shows a comparison of the concentrations of metals obtained from the lagoon, Woodbrook and the final effluents of the local sewage works. Results for TSS and dissolved solids (expressed via EC) are also shown. The data show higher concentrations of total zinc deriving from the motorway compared to the other sources, which suggests that tyre wear could be a source of zinc in the environment. For example, when typical sources of zinc into one of the Stockholm's STW were compared, it was found that tyres could contribute up to $9 \%$ of $\mathrm{Zn}$ to its total quantity of $\mathrm{Zn}$ (Sorme and Lagerkvist, 2002).

The situation with the STWs, however, is variable, since the degree of pollutant enrichment in a water body will depend upon the amount of dilution received. For example, Comber et al. 2020 confirmed this while analysing 170 STWs across England and Wales and finding that treatment efficiency and geography could also affect the variations of pollutant concentrations. Thus, although the data show that $\mathrm{Cu}_{\text {dis }}$ from one of the sewage treatment works (STW B) exceeded the previous and current EQS (which can be explained in terms of the common use of copper in domestic water systems), the capacity of the receiving water body also needed to be taken into account. Sorme and Lagerkvist (2002) reported that the relative contribution of Cu from pipes and 
taps to a typical STW could comprise up to $66 \%$ of the total Cu quantity, only up to $5 \%$ of which related to traffic, deriving from brake pads.

Nevertheless, when the data from Table 6 are analysed it is impossible to overlook the striking value recorded for the total amount of copper during the January event, which was $0.161 \mathrm{mg} / \mathrm{l}$. At the time of sampling and analysis, the dissolved fraction of copper was very low, at $0.002 \mathrm{mg} / \mathrm{l}$, but under different circumstances (due to variation on the water parameters in the lagoon increasing $\mathrm{pH}$ and temperature, for example), the proportion could change. This suggestion could be further supported by Sansalone and Buchberger's results which showed that the ratio of dissolved to particulate copper was initially $1 / 5$ but changed over 24 hours and became $1 / 1\left(\mathrm{Cu}_{\text {tot }}\right.$ was $0.3 \mathrm{mg} / \mathrm{l})$. This example served to underline the importance of pre- and post-storm analysis. Interestingly enough, Ziolko et al. 2009 observed the completely opposite trend in the change in copper partitioning at a STW - from dissolved to particulate. In their case, return activated sludge (RAS) was mixed with crude sewage, which resulted in an alteration in the behaviour of copper. It became bound with particulate matter and was effectively removed from PST (primary sedimentation tank) together with TSS.

From all the Tables in which highway runoff compared with that from other sources, one can see that it is the major source of metals into the catchment. At the same time urban runoff and sewage works do contribute a substantial amount of metals as well. It is also important to take into consideration the ability of metals to change their ratio (total/dissolved) due to a number of reasons which have been stated above.

\section{Surface discharge criteria}

When comparing the M1 concentrations with those from the STWs it should be noted that with regard to the M1 the standards should be applied to the lagoon itself, whereas for the STWs a factor of dilution should be taken into consideration (Bubb and Lester, 1995). The lagoon in this case should be treated not only as a final stage of treatment but at the same time as a natural water body, where the treated runoff is discharged. It is worth noting that the mixing effect is slow, as the water in the lagoon is quiescent.

A further demonstration of the importance of a robust system understanding, while applying the EQS, can be seen when comparing the data arising from the M1 runoff treatment system with data from a treatment system on the M40 motorway which has previously been monitored by Crabtree et al. (2006). Table 7 provides such a comparison. The most important difference between these systems is that for the M1 the discharging water body is the lagoon, whereas for the M40 the discharge flows to Souldern brook; the M1 system is, thus, more sensitive and 
vulnerable as the EQS should be apply at the lagoon itself being a final stage of the treatment system. The results also show that on average this standard SuDS system (interceptor and lagoon) had a satisfactory treatment effect and achieved background concentrations of metals. The old EQS were formally stricter and less favourable for the dischargers. One of the parameters which was always monitored during the field study was $\mathrm{pH}$, which affects metal bioavailability. The $\mathrm{pH}$ was relatively stable during and between different storm events ( $\mathrm{pH}$ from 6.8 to 7.9) which implies that the revised EQS is adequate. It also suggests that the old EQS $\left(\mathrm{Zn}_{\mathrm{tot}}\right.$, see Fig. $\left.4 \mathrm{c}\right)$ would tend to imply a larger risk, which could be counteracted technically (by installing more expensive and sensitive treatment facilities).

Table 7 Comparison of pollutant removal

\begin{tabular}{|c|c|c|c|c|c|c|c|c|c|c|}
\hline \multirow{3}{*}{$\begin{array}{l}\text { Sample } \\
\text { points }\end{array}$} & \multicolumn{10}{|c|}{ Average concentration of pollutants, $\mathrm{mg} / \mathrm{l}$} \\
\hline & \multicolumn{5}{|c|}{ M1/Lagoon* } & \multicolumn{5}{|c|}{ M40/Souldern Brook** } \\
\hline & $\mathrm{Zn}_{\text {tot }}$ & $\mathrm{Zn}_{\mathrm{dis}}$ & $\mathrm{Cu}_{\text {tot }}$ & $\mathrm{Cu}_{\mathrm{dis}}$ & TSS & $\mathrm{Zn}_{\text {tot }}$ & $Z n_{\text {dis }}$ & $\mathrm{Cu}_{\text {tot }}$ & $\mathrm{Cu}_{\mathrm{dis}}$ & TSS \\
\hline $\begin{array}{l}\text { Highway } \\
\text { runoff*** }\end{array}$ & 0.175 & 0.035 & 0.084 & 0.012 & 75.7 & 0.1 & 0.025 & 0.025 & 0.01 & 75 \\
\hline $\begin{array}{l}\text { Runoff } \\
\text { immediately } \\
\text { after the } \\
\text { interceptor }\end{array}$ & 0.175 & 0.044 & 0.061 & 0.012 & 47.1 & 0.09 & 0.012 & 0.02 & 0.01 & 75 \\
\hline $\begin{array}{l}\text { Discharging } \\
\text { to water } \\
\text { body**** }\end{array}$ & 0.048 & 0.020 & 0.016 & 0.004 & 11.6 & 0.04 & 0.006 & 0.008 & 0.005 & 25 \\
\hline
\end{tabular}

A further feature of these data was that $\mathrm{Cu}$ was always found to exhibit the lowest concentration of all the metals. The $\mathrm{Cu}$ concentrations from both the M1 and M40 studies were lower than those reported from urban traffic, in line with the results from previous research (Hulscotte et al., 2007). The conclusion drawn from this is that, whereas in urban driving conditions copper is generated more frequently while the vehicles are braking, the M1 and M40 tend to have continuously moving traffic. Another possible explanation, as proposed by Zhang et al. (2015), is that the presence of a considerable proportion of the $\mathrm{Cu}$ in stormwater runoff will depend on the removal of roaddeposited sediment. In this study, as has already been mentioned, the first sample point was situated where the highway runoff left the highway itself and reached the inlet, meaning that it had passed through a filter trench, where a substantial amount of debris was retained. 
The concentrations of the metals from the M1 are higher than those observed at the M40 site, which can be explained by the greater traffic flow on the $M 1(30,000$ vehicles per hour, compared with 15,000 vehicles/hour on the M40).

The foregoing demonstrates that in evaluating the performance of a treatment system, it is crucially important to bear in mind the fact that stormwater management continues to evolve and to undergo significant changes. It is, thus, necessary to embrace a broad area of knowledge from flood mitigation to water quality improvement and the reduction of soluble pollutants when designing/optimising a runoff treatment system. This is increasingly important in view of the addition of the bioavailability concept to the revised EQS. Understanding the system design is critically important, as the application of the EQS to monitoring data without an appropriate understanding of the system having first been acquired will result in a significant misclassification of the risk from whatever metal may be present in the water at a site.

De-icing salt's impact on metals' behaviour

We can infer that a pulse of dissolved zinc has been released from the interceptor in conjunction with the elevated sodium from de-icer applications, which took place during winter time. Figure 5 shows the percentage of dissolved $\mathrm{Zn}$ with the $\mathrm{Na}$ concentration in samples taken after a rainfall event (the post-storm period of time). There is a distinctive peak of $\mathrm{Zn}$ and $\mathrm{Na}$ in the holding chamber of the interceptor, which should be considered together with the finding that only $2 \%$ of $\mathrm{Zn}$ was bound in the particulate matter (greater than $0.45 \mu \mathrm{m}$ ). Previous studies have shown that adding de-icer can increase colloidal mobility and ion competition. For example, the results obtained by Norrstrom (2005) when analysing the effect of de-icing salt on metal mobility and behaviour in highway runoff for groundwater, coincide very well with ours, according to which $5 \%$ of $\mathrm{Zn}$ was bound in the particle phase in the column leachates and a rising $\mathrm{Zn}$ concentration was correlated with $\mathrm{NaCl}$ leachate. This indicates that de-icing salt is likely to promote $\mathrm{Zn}$ availability through the mobilisation of small-sized colloidal particles or ion competition. The availability of ions in the soil solution is a dynamic phenomenon, which is affected by different parameters in the system. One of the factors that plays a key role in this is the ionic strength. lonic strength affects soil particles by changing the surface potential/surface charge of colloidal particles and thereby affecting the diffusive double layer. The higher the ionic strength (concentration of dissolved ions), the more condensed the diffusive double layer becomes. In other words, when the ionic strength increases, we see fewer electrostatic interactions between colloidal soil particles (Pouran et al., 2014). One possibility is this phenomenon/mechanism could lead to detachment/disintegration of the soil colloidal particles from each other, which in the end improves colloidal mobility. The ions, 
which are attached to the surface of colloids, would also be affected in this way. The other possibility that we could consider is the prevalence of ionic competition. Adding de-icer may increase the ionic competition and consequently lead to the replacement of the ions on the surface of the soil particles with new ones (added because of the de-icer) (Pouran et al., 2017).

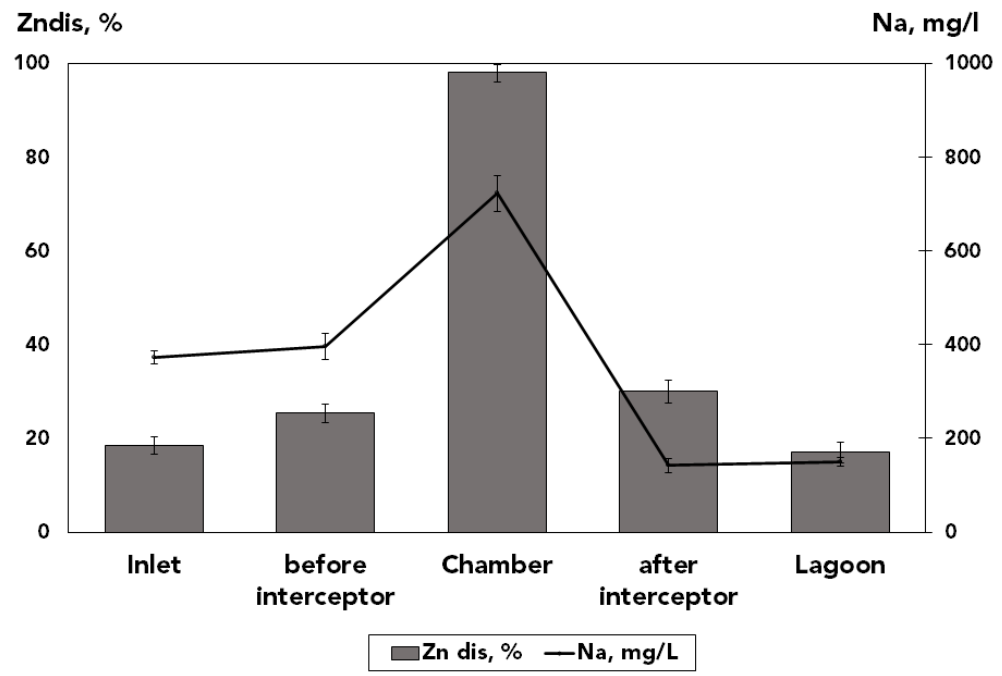

Fig. 5 Metal profiles through the SuDS system during a cold winter post-storm $\left(\mathrm{Zn}_{\text {tot }}\right.$ is $0.155 \mathrm{mg} / \mathrm{l}$ in the chamber with TSS $9.0 \mathrm{mg} / \mathrm{l}$ )

These two examples help us to understand the principal mechanisms by means of which metal species are captured in highway runoff and, more importantly, under which circumstances metals may leach from the treatment system, leading to the possible pollution of groundwater.

Furthermore, it can be seen that the EQS should be taken into consideration a lot more rather than being regarded as merely a value against which an obtained concentration will be compared. This supports the decision to include two more parameters ( $\mathrm{pH}$ and $\mathrm{DOC}$ ) in the new EQS in order to evaluate Zn's impact on water bodies (UKTAG, 2013).

The $\mathrm{Na}$ concentration is higher from the treated M1 discharge compared to Woodbrook (Table 6), which is likely to have been the result of de-icing operations which took place at the time of sampling. It decreases during rainfall events due to dilution, but it is persistent because of its long residence times in the lagoon (30 days at average rainfall).

\section{Conclusions}

In this study highway runoff was distinguished as a major contributor of metals into the catchment compared to urban runoff originated from Woodbrook and sewage works representing the same catchment. Nevertheless, these two sources can also contribute a substantial amount of metals into the water environment. Event monitoring in the receiving water (lagoon) showed that highway runoff had no immediate impact on metals' behaviour over their background 
concentrations. The monitoring of rainfall events indicated that metal concentrations and solubility do not change immediately. Knowledge of pre- and post-storm conditions and ADWP in particular is critically important for a correct understanding of metals' behaviour and of their fate e.g. their solubility and mobility because of the re-suspension of the sediment generated by previous rain. In addition, continued work is essential if a reliable assessment is to be gained of such dynamic systems as runoff water discharge and treatment.

This study showed that the metals' solubility was, in descending order, $\mathrm{Zn}>\mathrm{Cu}>\mathrm{Fe}$ during both dry and wet weather, although during dry weather the dissolved concentrations of the studied metals becomes higher due to water evaporation.

Fe had the highest concentrations (both total and dissolved) for all weather conditions and in all sampling locations. $\mathrm{Cu}_{\text {dis }}$ concentrations varied greatly and were among the lowest concentrations observed in the metals studied. The copper concentration was also lower than the results reported in previous studies because $\mathrm{Cu}$ is generated during vehicle braking, whereas the M1 generally has continuously moving traffic.

This research suggests that natural phenomenon such as cold weather and, consequently, de-icer application could affect water quality and metal speciation in the lagoon. In particular, $\mathrm{Zn}$ availability was found to be high (98\%) following winter salting (adding $\mathrm{NaCl}$ ) due to both colloidal mobility and cation exchange. The revised (new) EQS are sufficiently robust under a range of environmental conditions, such as rainfall events and ADWP.

\section{Acknowledgements}

This research was supported by Loughborough University and partially supported by SUE 'Vodokanal of St. Petersburg'. We thank Mr Geoff Russell and Mrs Jayshree Bhuptani for assistance with laboratory and field support. We are immensely grateful to Prof David Butler, University of Exeter, for his comments on an earlier version of the manuscript. We also recognise the fact that without the support provided by Mr David Chapman, Mr Dhan Tagie, Mr Dmitry Zakharov the publication of this paper would not have been possible.

\section{Disclosure statement}

No potential conflict of interest was reported by the authors. 


\section{References}

APHA (2005) Standard methods for the examination of water and wastewater. $21^{\text {st }}$ ed. Washington, DC: American Public Health Association.

Bubb, J.M.; Lester, J.N.; 1995: The effect of final sewage effluent discharges upon the behaviour and fate of metals in a lowland river system. A question of dilution? Environ. Tech. 16: $401-417$.

Butler D, Balmforth D, Digman C, Kellagher R. (2006) Designing for exceedance in urban drainage - good practice, CIRIA Report C635.

Crabtree, B.; Moy, F.; Whitehead, M.; Roe, A. (2006) Monitoring pollutants in highway runoff. J. Ch. Instn. Wat.\& Envir. Mangt., 20: 287-294.

Comber, S.D.; Gardner, M.J.; Churchley, J. (2005) Aluminium speciation: implications of wastewater effluent dosing on river water quality. J.Chem. Spec.\& Bioaval. 17(3): $117-128$.

Comber, S.D.; Gardner, M.J.; Ellor, B. (2020) Seasonal variations of contaminant concentrations in wastewater treatment works effluents and river waters. J. Environ. Technol., 41 (21): 2716 - 2730.

Council of European Communities (1976). Directive on pollution caused by certain dangerous substances discharged in the aquatic environment of the Community (76/464/EEC). Official Journal L129 18 May 1976

Dang, V.M.; Joseph, S.; Van, H.T.; Mai, T.L.A.; Duong, T.M.H.; Weldon, S'; Munroe, P.; Mitchell, D.; Taherymoosavi, S. (2019) Immobilisation of heavy metals in contaminated soil after mining activity by using biochar and other industrial by-products: the significant role of minerals on the biochar surfaces. J. Environ. Technol., 40 (24): 3200 - 3215.

Geronimo, F.K.F,; Maniquiz_Redillas, M.C.; Tobio, J.A.S.; Kim, L.H. (2014) Treatment of suspended solids and heavy metals from urban stormwater runoff by a tree box filter. Water Sci Technol. 69 (12), $2460-2467$.

Gnecco, I.; Berretta, C.; Lanza, L. G.; LA Barbera, P. (2005) Storm water pollution in the urban environment of Genoa, Italy. Atmospheric Res. 77: $60-73$.

Great Britain Department for Transport (DFT), Highways Agency, 2001, Design Manual for Roads and Bridges (DMRB) Volume 10 - Environmental Design, HMSO, ISBN 9780115516443, available at http://www.standardsforhighways.co.uk/ha/standards/dmrb/vol10/index.htm, accessed 23 ${ }^{\text {rd }}$ March 2020.

Great Britain Department for Transport (DFT), Highways Agency, 2017, Design Manual for Roads and Bridges (DMRB) Volume 4 - Geotechnics and Drainage, HMSO, available at http://www.standardsforhighways.co.uk/ha/standards/dmrb/vol4/section2/ha3717. pdf, accessed $8^{\text {th }}$ December 2018.

Hallberg, M.; Renman, G.; Lundbom, T.; 2007: Seasonal variations of ten metals in highway runoff and their partition between dissolved and particulate matter. Water Air Soil Pollut. 181: 183 - 191.

Hulscotte, J.H.J.; Denier van der Gon, H.A.C.; Visschedijk, A.J.H.; Schaap, M. (2007) Brake wear from vehicles as an important source of diffuse copper pollution. Environ. Sci. Technol J. 56: $223-231$.

Kayhanian M., Suverkropp C., Ruby A., Tsay K. (2007) Characterisation and prediction of highway runoff constituent event mean concentration. J. Envir. Mangt., 85: 279-295.

LI, 2014. Management and maintenance of Sustainable Drainage Systems (SuDS) landscapes. LI Technical Guidance Note 01/2014. Available at https://www.landscapeinstitute.org/wp-content/uploads/2015/12/TGN1_14SUDSmanagementMar2014.pdf. Accessed $8^{\text {th }}$ December 2018

Ling, L.; Guo, X.; Zhang, C.; Luo, C.; Li, R. (2018) Adsorption behaviours and mechanisms of heavy metal ion's impact on municipal wate composts with different degree of maturity. J. Environ. Technol., 40 (22): 1 - 43.

Nelson, S.S.; Yonge, D.R.; Barber, M.E.; 2009: Effects of road salts on heavy metal mobility in two Eastern Washington soils. J. Environ. Eng.; 135: $505-510$.

Niu, S.; Wang, X.; Yu, J.; Kim, Y. (2018) Pollution reduction by recirculated fill-and-drain mesocosm wetlands packed with woodchip/pumice treating impervious road stormwater. J. Environ. Technol., 41 (13): 1627 - 1636.

Norrstrom, A.C. (2005) Metal mobility by de-icing salt from an infiltration trench for highway runoff. J. Appl. Geochem.; $20: 1907$ - 1919.

Pagotto, C.; Legret, M.; Le Cloirec. P. (2000) Comparison of the hydraulic behaviour and the quality of highway runoff water according to the type of pavement. Wat. Res. 34 (18), $4446-4454$.

Pagotto, C.; Remy, N,; Legret, M.; Le Cloirec. P. (2001) Heavy metal pollution of road dust and roadside soil near a major rural highway. J. Environ. Technol., 22 (3): $307-319$.

Pouran, H.M.; Martin F. L.; Zhang H. (2014) Measurement of ZnO Nanoparticles using diffusive gradients in thin films: binding and diffusional characteristics. J. Anal. Chem. 86 (12), 5906-5913.

Pouran, H.M.; Steve A. Banwart, S.A.; Romero-Gonzalez, M. (2017) Effects of synthetic iron and aluminium oxide surface charge and hydrophobicity on the formation of bacterial biofilm. J. Environ. Sci.: Processes Impacts. 19, 622-634.

Rossin, A.C., Sterritt, R.M., Lester, J.N. (1983) The influence of flow conditions on the removal of heavy metals in primary sedimentation process. Water Air, Soil Pollut. 19, $105-121$. 
Sansalone, J.J.; Buchberger, S.G. (1997) Partitioning and first flush of metals in urban roadway storm water. J. Environ. Eng., ASCE, 123:134 - 143.

Sorme, L.; Lagerkvist, R. (2002) Sources of heavy metals in urban wastewater in Stockholm, Sci Total Environ. 298,131 - 145.

UKTAG (2013); Updated Recommendations on Environmental Standards; River Basin Management (2015 - 2021); Final Report November 2013; (Minor amendments January 2014).

http://www.wfduk.org/sites/default/files/Media/Environmental\%20standards/UKTAG\%20Environmental\%20Standards\%20Phase\%203\%20Final\%2 0Report\%2004112013.pdf

USGS (2000): A Synopsis of Technical Issues of Concern for Monitoring Trace Elements in Highway and Urban Runoff. United States Geological Survey and US Department of Transportation (Open-file report $00-422$ ): USA.

Zhang, J.; Hua, P.; Krebs, P. (2015). The chemical fractionation and potential source identification of Cu, Zn and Cd on urban watershed. Water Sci Technol. 72 (8), $1428-1436$.

Ziolko, D.; Lester, J.N.; Scrimshaw, M.D. (2009) Evaluation of copper removal during sewage treatment. Sci Total Environ. 407.6235 - 6241. 